\title{
IDENTIFIKASI JALUR EVAKUASI BENCANA DI GUNUNG KELUD KABUPATEN BLITAR
}

\author{
Widiyanto Hari Subagyo Widodo $^{1}$, Annisaa Hamidah Imaduddina ${ }^{2)}$, Ida Soewarni ${ }^{3)}$, Ibnu Sasongko ${ }^{4)}$ \\ ${ }^{122) 3) 4)}$ Fakultas Teknik Sipil dan Perencanaan, Institut Teknologi Nasional Malang \\ email: widiayanto@ftsp.itn.ac.id
}

\begin{abstract}
Abstrak
Gunung Api Kelud merupakan salah satu gunung aktif yang berada di Kabupaten Blitar, Provinsi Jawa Timur. Pada tahun 2014 terjadi erupsi Gunung Kelud yang menyebabkan 7 jiwa meninggal dan puluhan ribu jiwa harus mengungsi. Upaya meminimalisir risiko bencana dapat dilakukan dengan dilakukannya penentuan jalur evakuasi bencana Gunung Kelud. Dalam mengoptimalkan hasil kajian, dibutuhkan partisipasi masyarakat dalam mengambil keputusan dan merumuskan tindakan prioritas pengurangan risiko bencana. Penentuan jalur evakuasi dalam penelitian ini dilakukan dengan menggunakan metode analytic hierarchy process. Berdasarkan hasil kajian ini, dihasilkan bahwa Desa Maliran di Kecamatan Ponggok, Desa Semen dan Desa Soso di Kecamatan Gandungsari merupakan tempat evakuasi sementara terpanjang di Kabupaten Blitar. Adapun hasil kajian ini diharapkan dapat menjadi masukan untuk perencanaan kawasan Kabupaten Blitar yang berbasis pengurangan risiko bencana.
\end{abstract}

Kata Kunci: Erupsi, Gunung Kelud, Jalur evakuasi, Kabupaten Blitar

\begin{abstract}
Mount Kelud is an active volcano in Blitar Regency, East Java Province. In 2014, the eruption of Mount Kelud occurred which caused 7 people to die and tens of thousands of people had to flee. Efforts to minimize disaster risk can be done by determining the evacuation route for Mount Kelud disaster. In optimizing the results of the researh, community participation in making decisions and formulating priority actions for disaster risk reduction is needed. The determination of the evacuation route in this research was carried out using the analytic hierarchy process method. Based on the results of this research, it was found that Maliran Village in Ponggok District, Semen Village and Soso Village in Gandungsari District were the longest temporary evacuation sites in Blitar Regency. The results of this research are expected to be input for planning the Blitar Regency area based on disaster risk reduction.
\end{abstract}

Keywords: Eruption, Mount Kelud, Evacuation route, Blitar Regency

\section{PENDAHULUAN}

Gunung api merupakan suatu saluran yang mengeluarkan magma ke permukaan bumi. Bahaya yang ditimbulkan akibat adanya letusan gunung api dapat dirasakan secara langsung (premier) dan tidak langsung (sekunder) oleh masyarakat. Bahaya yang dirasakan secara langsung oleh masyarakat diantaranya lava pijar, bongkahan piroklasatik, dan gas beracun. Bahaya yang kecil kemungkinan atau tidak secara langsung terjadi adalah banjir bandang dan longsoran material vulkanik. 
Letak Gunung Kelud berada di Kabupaten Blitar, Provinsi Jawa Timur. Salah satu gunung api yang aktif ini memiliki aktivitas vulkanik dengan potensi letusan setiap 20 tahunan (Wardana, 2014 dalam Bachri 2017). Hal ini diperkuat dengan adanya data histori terjadinya erupsi gunung tersebut. Letusan yang terjadi sejak tahun 1000 hingga tahun 2014 menurut data ESDM dan PVMB terjadi sebanyak 31 kali erupsi. Pada tahun 2014 terjadi erupsi yang menyebabkan 7 korban jiwa meninggal dan 83.347 jiwa mengungsi. Kegiatan vulkanik ini juga menyebabkan terjadinya kerusakan rumah - rumah warga yang berada di kaki gunung tersebut.

Upaya meminimalisir risiko bencana dapat dilakukan dengan menentukan jalur evakuasi bencana di sekitar Gunung Kelud. Hal ini dilakukan agar mempersingkat proses pengungsian untuk masyarakat sekitar menuju ke tempat yang tidak terdampak oleh aktivitas vulkanik tersebut. Mobilisasi masyarakat terhadap ancaman bahaya gunung berapi dengan jalur evakuasi memiliki 2 tahapan. Kedua tahapan tersebut berdasarkan Draft VII Standar Penataan Ruang di Kawasan Rawan Bencana tahun 2014 terdiri dari evakuasi masyarakat dari permukiman ke tempat evakuasi sementara (TES) dan dari tempat evakuasi sementara menuju tempat evakuasi akhir (TEA).

\section{KAJIAN LITERATUR}

\subsection{Bencana}

Bencana dapat diartikan sebagai kegiatan yang menimbulkan ancaman bagi kehidupan yang diakibatkan baik adanya faktor alam ataupun faktor non-alam dengan mengakibatkan adanya kerusakan ekosistem. Hal ini terjadi secara tiba - tiba dengan tidak dapat di prediksi waktu terjadinya. Adapun bencana yang dimaksudkan diantaranya tsunami, kekeringan, gempa bumi, dan banjir.

Hal yang dapat dilakukan dalam meminimalisir kerusakan akibat terjadinya suatu bencana adalah dengan memahami faktor - faktor terjadinya bencana tersebut. adapun faktor - faktor tersebut diuraikan sebagai berikut.

\section{Faktor Alam}

Bencana yang diakibatkan oleh adanya aktivitas bumi dengan bersifat alamia dan tidak terdapat pengaruh dari berbagai hal diantaranya gempa bumi, erupsi gunung, angin topan, dan tsunami.

2. Faktor Non-alam

Bencana yang diakibatkan adanya kegiatan yang bersifat non-alamia diantaranya wabah, perang, dan adanya kerusakan akibat kesalahan pemanfaatan teknologi.

Berdasarkan uraian di atas, dalam meminimalisir terjadinya bencana dibutuhkan suatu perencanaan mitigasi bencana. Hal ini diharapkan agar risiko yang ditimbulkan dari bencana - bencana tersebut sangat kecil. Adapun dalam melakukan perencanaan mitigasi bencana dilakukan dengan prinsip yang diuraikan sebagai berikut.

a. Mitigasi bencana dilakukan agar memperkecil risiko bencana serupa dan pernah terjadi sebelumnya;

b. Keterlibatan banyak pihak sangat dibutuhkan dalam mewujudkan mitigasi bencana yang bersifat kompleks;

c. Efektivitas mitigasi bencana terjadi dengan adanya mitigasi yang aktif;

d. Kelompok rentan merupakan prioritas dalam mitigasi bencana yang memiliki sumberdaya yang terbatas;

e. Evaluasi berkala dalam mitigasi diperlukan agar dapat melihat adanya suatu perubahan kondisi.

Pola mitigasi bencana mengalami perubahan, yaitu adanya perubahan pola pikir dari konvensional ke mitigasi yang melihat secara menyeluruh dari hulu menuju hilir perencanaan. Pola pikir secara konvensional dimaksudkan bahwa korban yang ditimbulkan oleh bencana harus segera dievakuasi, hal ini dapat disimpulkan bahwa mitigasi bencana merupakan suatu tindak pertolongan. Pembaharuan pola pikir dalam mitigasi bencana dilakukan secara menyeluruh dari hulu ke hilir. Hal ini dapat diartikan bahwa mitigasi bencana dilakukan dari identifikasi kawasan dan memahami pola yang menyebabkan rawan bencana. Mitigasi lebih dilakukan secara struktural seperti adanya penataan ruang dan penyusunan peraturan zonasi di kawasan bencana.

\subsection{Bencana Letusan Gunung Api}

Secara teknis gunung api merupakan tempat keluarnya material vulkanik ke permukaan bumi dengan kedalaman $10 \mathrm{~km}$ di 
bawah permukaan bumi. Material yang dikeluarkan saat gunung meletus juga termasuk endapan hasil akumulasi material. Material - material yang keluar saat terjadinya gunung meletus berwujud cair dan dinamakan lava (Supriyono, 2014).

Bahaya yang harus dihindari yaitu berupa batuan, lava, dan gas yang ditimbulkan saat terjadinya letusan gunung. Hal inilah yang menyebabkan adanya korban jiwa dan kerugian harta benda (Djauhari, 2011). Akan tetapi, adanya bencana letusan gunung juga memiliki dampak positif bagi ekosistem. Adapun dampak positif maupun negatif, serta bahaya dari bencana letusan gununng diuraikan sebagai berikut.

1. Dampak Letusan Gunung Api

Uraian dari dampak positif dan negatif akibat terjadinya letusan gunung api disajikan sebagai berikut.

a. Dampak Negatif:

1) Dampak yang dirasakan secara langsung saat terjadi bencana letusan gunung adalah awan panas, lava, dan gas beracun yang membahayakan manusia dan makhluk hidup lainnya;

2) Dampang yang tidak secara langsung dirasakan saat terjadinya bencana letusan gunung adalah kerusakan penggunaan lahan di sekitar gunung berapi, pencemaran air dan udara, serta trauma bagi masyarakat sekitar.

b. Dampak Positif:

1) Tersedianya material yang dapat dimanfaatkan dalam kehidupan sehari - hari seperti bahan galian seperti batu dan pasir, bahan mineral seperti belerang, gypsum, zeolite dan juga mas (epitermal gold);

2) Terdapat mata air panas akibat adanya panas bumi yang juga dapat dikembangkan sebagai kawasan wisata;

3) Dapat dimanfaatkan sebagai kawasan pertanian karena adanya endapan lava yang mengakibatkan tanah subur disekitar gunung api.

2. Bahaya Gunung Api

Adapun bahaya dari letusan gunung api diuraikan sebagai berikut.

a. Awan panas
1) Awan panas yang ditimbulkan saat terjadinya erupsi memiliki suhu 200 hingga $800^{\circ} \mathrm{C}$, dengan kecepatan dari 60 hingga $145 \mathrm{~km} / \mathrm{jam}$ dengan radius jangkauan \pm mencapai $10 \mathrm{~km}$ dari pusat erupsi. Adapun bahaya dari awan panas ini dapat memporak porandakan bangunan serta pohon pohon tumbang dan tercabut hingga akarnya;

2) Awan panas memiliki 2 tipe yang mempengaruhi arah jatuhnya. Adapun tipe tersebut diantaranya "Block and Ash Flow" yang artinya jatuh mengikuti bentuk lembah, sedangkan "Surge" memiliki arah yang luas dan mengakibatkan tertutupnya morfologi pada lereng gunung api, sehingga radius yang terdampak jauh lebih luas.

b. Longsoran Lava

Longsoran lava yang terjadi saat erupsi mencapai jutaan meter kubik yang sangat berisiko dan membahayakan ekosistem. Radius longsoran dan runtuhan material batuan bergantung pada tenaga yang ditimbulkan dan tipe saat terjadinya erupsi.

c. Lontaran Batu Pijar

Saat terjadi erupsi, juga terjadi lontaran batuan gunung api yang bersifat sangat panas dan menyebar keseluruh arah. Hal ini memiliki risiko tinggi sebagai penyebab terjadinya kebakaran hutan yang ada disekitar kaki gunung tersebut dan mengakibatkan kerusakan ekosistem di wilayah sekitar.

\section{d. Hujan Abu}

Saat terjadi erupsi, juga terjadi hujan material berukuran butiran pasir yang menyebabkan udara disekitar menjadi gelap, jalan yang licin berpasir, kesehatan masyarakat sekitar terganggu, pertanian menjadi rusak, dan mengganggu aktivitas penerbangan yang hendak melintasi kawasan sekitar erupsi gunung tersebut.

\subsection{Mitigasi Bencana Gunung Meletus}

Seperti yang diuraikan sebelumnya, mitigasi dibedakan menjadi 2 yaitu structural dan non-struktural. Mitigasi struktural yang dimaksud adalah menciptakan rekayasa bangunan dengan konsep anti gempa dan tidak akan hancur akibat adanya awan panas dan dialiri lahar. Adapun mitigasi non-struktural dilakukan dengan memberikan alat 
pemantauan aktivitas gunung api dan alarm peringatan dini erupsi, serta menyediakan dam yang dapat meminimalisir banjir lahar. Upaya yang dapat dilakukan saat mitigasi bencana letusan gunung dapat diuraikan sebagai berikut (Supriyono, 2014).

\section{Pemetaan Daerah Rawan}

Adanya pemetaan kawasan rawan bencana letusan gunung api dapat dijadikan landasan kebijakan pemerintah setempat. Tidak hanya dijadikan landasan kebijakan, pemetaan rawan bencana juga dapat digunakan untuk menyadarkan masyarakat terkait bahaya bencana tersebut. Kejadian-kejadian gunung meletus pada masa lampau tentu sangat berguna untuk menyusun rencana dan tindakan mitigasi bencana gunung meletus disuatu daerah.

2. Pembuatan Prediksi

Berdasarkan serangkaian kejadian dan pola kecenderungan berulangnya kembali bencana gunung meletus, dapat dibuat berulangnya kembali bencana gunung meletus, dapat dibuat semacam prediksi gunung meletus yang akan terjadi.

\section{Pendidikan dan Latihan}

Peningkayan kesadaran, pengetahuan dan keterampilan mitigasi bencana gunung meletus, maka perlu dilakukan pelatihan simulasi pada semua kelompok masyarakat rentan terhadap bencana.

4. Relokasi Permukiman

Adanya peta rawan bencana juga dapat dimanfaatkan sebagai acuan penataan permukiman di kawasan sekitar. Permukiman yang rentan terdampak erupsi gunung diperlukan relokasi ke wilayah yang tidak terdampak

\section{Pembuatan Aturan Konstruksi}

Kelayakan konstruksi bangunan dengan kemampuan yang tahan gempa perlu ditetapkan dengan peraturan pemerintah di kawasan rawan bencana. Hal ini dimaksudkan agar adanya batasan ketinggian dan kemiringan atap bangunan maksimal yang diperbolehkan dalam kawasan tersebut.

6. Pembuatan Jalur dan Rambu Evakuasi

Penyediaan prasarana seperti jalur dan lokasi evakuasi dimaksudkan apabila terjadi bencana letusan gunung dapat meminimalisir korban.

7. Pembentukan Satuan Tugas
Mitigasi bencana juga membutuhkan satuan tugas yang memiliki tupoksi jelas dan meilbatkan masyarakat sekitar agar terlaksana dengan optimal.

8. Penyediaan Peralatan

Adanya penyediaan alat mitigasi bencana sangat diperlukan saat terjadi bencana. Adapun alat - alat tersebut diantaranya, pemadam kebakaran, peralatan penggalian tanah, pelampung, dan peralatan lainnya.

\section{METODE PENELITIAN}

Metode analisis yang digunakan untuk mencapai tujuan penelitian berdasarkan sasaran penelitian diuraikan sebagai berikut.

\subsection{Identifikasi Faktor yang Berpengaruh}

\section{Terhadap Kawasan Rawan Bencana}

Agar memperoleh faktor - faktor yang berpengaruh dalam kerentanan bencana letusan Gunung Kelud, digunakan analisis deskriptif. Berdasarkan variabel yang terlah ditentukan dibandingkan dengan teori kebencanaan atau kondisi eksisting, digunakan analisis delphi pada responden yang telah ditentukan agar analisis yang dihasilkan optimal. Hasil dari analisis ini adalah fiksasi dari faktor - faktor yang berpengaruh terhadap kerentanan bencana letusan Gunung Kelud di Kabupaten Blitar.

Hasil analisis sebelumnya dilanjutkan dengan tahapan analisis AHP (Analytical Hierarchy Process). Tahapan ini dilakukan untuk menentukan faktor prioritas dengan memberikan bobot disetiap faktor oleh para stakeholder yang telah ditentukan sebagai narasumber. Stakeholder yang dimaksudkan diantaranya pemerintah, akademisi, serta praktisi yang ahli dalam bidang kebencanaan. Bobot yang diberikan dalam menentukan prioritas ini memiliki skala 1 sampai 9 (Saaty, 1993).

\subsection{Pemetaan Risiko Bencana Letusan \\ Gunung Kelud}

Pemetaan risiko bencana dihasilkan dari overlay antara peta bahaya dan kerentanan bencana yang mengancam suatu daerah. Perumusan risiko bencana berdasarkan persamaan berikut.

$$
\text { risiko }=H \times V
$$

Keterangan:

H: Bahaya (Hazard)

V: Kerentanan (Vulnerability) 


\subsection{Pemetaan Jalur Evakuasi Bencana Letusan Gunung Kelud}

Penentuan jalur mitigasi, ditentukan berdasarkan analisis risiko bencana yang terdiri dari beberapa aspek. Adapun aspek tersebut terdiri dari aspek kerentanan, aspek kapasitas, dan aspek ancaman bencana gunung api yang diolah menggunakan data administrasi dengan sumber BIG (Badan Informasi Geografis). Jalur mitigasi juga ditentukan dengan metode network analysis yang terdiri dari data jarak dan waktu tempuh lokasi, topografi, dan fasilitas disekitar pengungsian.

\section{HASIL DAN PEMBAHASAN}

\subsection{Identifikasi Faktor Berpengaruh Terhadap Bencana Letusan Gunung \\ Kelud}

Tahapan analisis yang dilakukan dalam mengidentifikasi faktor - faktor yang berpengaruh terhadap bencana letusan Gunung Kelud diuraikan sebagai berikut.

\subsubsection{Analisis Deskriptif}

\section{Analisis deskriptif yang dilakukan} dalam kajian ini adalah dengan membandingkan variabel terhadap teori maupun kondisi eksisting. Hal ini dilakukan untuk memperoleh faktor - faktor yang berpengaruh terhadap bencana letusan Gunung Kelud. Hasil analisis ini disajikan pada tabel 1.

\subsubsection{Anlisis Delphi}

Analisis delphi dilakukan sebagai fiksasi faktor - faktor yang berpengaruh terhadap kerentanan bencana letusan Gunung Kelud, yang diperoleh dari hasil konsensus para stakeholder sebagai narasumber. Faktor faktor ini digunakan sebagai penentuan tingkat kerentanan bencana. Adapun hasil analisis tersebut diuraikan sebagai berikut.

a. Aspek lingkungan: hutan lindung, semak belukar.

b. Aspek fisik: rumah, fasilitas umum, fasilitas kritis.

c. Aspek sosial: kepadatan penduduk, rasio jenis kelamin, rasio penduduk miskin, rasio kelompok umur.

d. Aspek Ekonomi: lahan produktif.

\subsubsection{Analisis AHP}

Penilaian ini dilakukan beberapa tahapan dalam penentuan kerentanan bencana letusan gunung. Hasil analisa AHP didapatkan nilai bobot faktor dalam penentuan kerentanan bencana letusan gunung dengan nilai inkonsistensi 0,07 sehingga faktor aspek lingkungan, aspek fisik, aspek ekonomi dan aspek sosial dianggap valid. Berikut adalah nilai bobot pada masing-masing faktor

a. Aspek Lingkungan adalah 0,209

b. Aspek Fisik adalah 0,253

c. Aspek Sosial adalah 0,299

d. Aspek Ekonomi adalah 0,239

Secara detail hasil analisis AHP disajikan pada gambar 1 . 
Tabel 1. Analisa Deskriptif

\begin{tabular}{lll}
\hline \multicolumn{1}{c}{ Variabel } & \multicolumn{1}{c}{ Teori / Kondisi Eksisting } & Faktor \\
\hline Aspek Lingkungan & \multicolumn{1}{c}{ Fungsi pokok kawasan hutan } & Hutan lindung di Kabupaten Blitar \\
& diantaranya sebagai penyangga & berada pada kaki Gunung Kelud \\
Hutan Lindung & kehidupan dalam menyimpan air, dengan luas 11.900,1 Ha yang \\
& meminimalisir banjir dan erosi, serta terdampak apabila terjadi letusan \\
& menjaga kesuburan tanah. & gunung \\
\hline
\end{tabular}

Semak belukar merupakan kawasan yang didominasi oleh tanaman

Semak Belukar beranting kecil dan rendah, dengan fungsi sebagai pengendali kekritisan lahan.

Semak belukar di Kabupaten Blitar tersebar di wilayah sekitar Gunung Kelud dengan luasan mencapai 4.999,2 $\mathrm{Ha}$ yang terdampak apabila terjadi letusan gunung

\begin{tabular}{ll}
\hline Aspek Fisik & \\
\hline Jumlah Rumah & $\begin{array}{l}\text { Jumlah rumah yang dinilai berdasarkan } \\
\text { kerentanan kerugiannya yang } \\
\text { diakibatkan oleh bencana. }\end{array}$ \\
\hline Jumlah Fasilitas Umum & $\begin{array}{l}\text { Jumlah fasilitas yang diadakan untuk } \\
\text { kepentingan umum, yang dinyatakan } \\
\text { dalam bentuk Rp. Rupiah (Rp). }\end{array}$ \\
\hline Fasilitas Kritis & $\begin{array}{l}\text { Fasilitas kritis yang dimaksud adalah } \\
\text { sabodam sebagai pengendali sedimen } \\
\text { atau material saat terjadi letusan } \\
\text { gunung. }\end{array}$
\end{tabular}

Rumah yang terdampak apabila terjadi bencana letusan gunung api mengalami kerugian sebesar Rp. $1.260 .000,00 / \mathrm{m}^{2}$

Fasilitas umum yang terdampak apabila terjadi bencana letusan gunung api mengalami kerugian sebesar Rp. 100 juta/unit

Fasilitas kritis yang dibangun mengalami kerugian saat terjadinya bencana letusan Gunung Kelud sebesar Rp. 10.000.000.000.000 /unit

\begin{tabular}{|c|c|c|}
\hline Aspek Sosial & & \\
\hline Kepadatan Penduduk & $\begin{array}{l}\text { Perbandingan jumlah penduduk } \\
\text { administratif dan luas wilayah tersebut. }\end{array}$ & $\begin{array}{l}\text { Kepadatan penduduk Kabupaten } \\
\text { Blitar yang terdampak apabila } \\
\text { terjadi bencana letusan gunung api } \\
\text { adalah } 793 \mathrm{jiwa} / \mathrm{km}^{2}\end{array}$ \\
\hline Rasio Jenis Kelamin & $\begin{array}{l}\text { Perbandingan jumlah penduduk } \\
\text { berdasarkan jenis kelamin yang tinggal } \\
\text { di } 1 \text { wilayah administratif. }\end{array}$ & $\begin{array}{l}\text { Rasio jenis kelamin di Kabupaten } \\
\text { Blitar yang terdampak terdampak } \\
\text { apabila terjadi bencana letusan } \\
\text { gunung api adalah } 100,4\end{array}$ \\
\hline $\begin{array}{l}\text { Rasio Penduduk Rumah } \\
\text { Tangga Miskin }\end{array}$ & $\begin{array}{l}\text { Perbandingan jumlah penduduk miskin } \\
\text { dan penduduk menengah ke atas. }\end{array}$ & $\begin{array}{l}\text { Rasio penduduk miskin di } \\
\text { Kabupaten Blitar yang terdampak } \\
\text { terdampak apabila terjadi bencana } \\
\text { letusan gunung api adalah } 8,94\end{array}$ \\
\hline Rasio Kelompok Umur & $\begin{array}{l}\text { Perbandingan antara jumlah penduduk } \\
\text { usia non produktif dan usia produktif. }\end{array}$ & $\begin{array}{l}\text { Rasio kelompok umur di } \\
\text { Kabupaten Blitar yang terdampak } \\
\text { terdampak apabila terjadi bencana } \\
\text { letusan gunung api adalah } 0,50\end{array}$ \\
\hline Aspek Ekonomi & & \\
\hline Lahan Produktif & $\begin{array}{l}\text { Luas lahan yang berbentuk sawah, } \\
\text { perkebunan, lahan pertanian dan tambak } \\
\text { yang produktifitasnya dinyatakan dalam } \\
\text { bentuk rupiah }(\mathrm{Rp}) \text {. }\end{array}$ & $\begin{array}{l}\text { Lahan produktif yang rentan } \\
\text { terhadap bencana letusan Gunung } \\
\text { Kelud memiliki nilai kerugian } \\
\text { sawah teridentifikasi } \quad \text { Rp. }\end{array}$ \\
\hline
\end{tabular}




\begin{tabular}{|c|c|c|}
\hline Variabel & Teori / Kondisi Eksisting & Faktor \\
\hline & & $\begin{array}{l}500.000 / \mathrm{m}^{2} \text {, kebun }\left(450.000 / \mathrm{m}^{2}\right), \\
\text { dan hutan produksi }\left(550.000 / \mathrm{m}^{2}\right)\end{array}$ \\
\hline
\end{tabular}

Sumber: Hasil Analisis Tahun 2020

20.9\% Aspek Linqkunqan (L: ,209)

25,3\% Aspek Fisik (L: ,253)

29.9\% Aspek Sosial (L: .299)

23,9\% Aspek Ekonomi (L: .239)

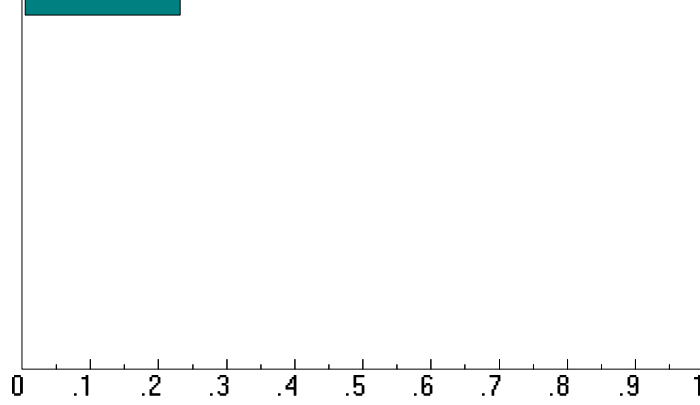

$10.2 \%$ Hutan Lindung

$5,1 \%$ Semak Belukar

$12.3 \%$ Rumah

7.8\% Fasilitas Umum

9.8\% Fasilitas Kritis

$12,4 \%$ Kepadatan Penduduk

7.3\% Rasio Jenis Kelamin

14,6\% Rasio Penduduk Rumah Tanqqa Miskin

8.8\% Rasio Kelompok Umur

$11.7 \%$ Lahan Produktif

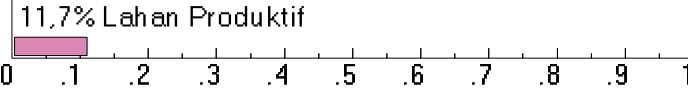

Sumber: Hasil Analisis Tahun 2020

Gambar 1. Dynamic Sensitivity for nodes below: AHP Faktor Kerentanan Bencana Letusan Gunung Kelud 


\subsection{Risiko Bencana Letusan Gunung Kelud di Kabupaten Blitar}

Risiko bencana merupakan tingkat kerusakan dan kerugian yang ditimbulkan akibat peristiwa alam. Risiko bencana ditentukan berdasarkan persamaan perkalian faktor bahaya dan kerentanan. Bahaya merupakan probabilitas dan besaran yang dapat diantisipasi pada peristiwa alam. Kerentanan dipengaruhi faktor lain seperti politik, ekonomi, sosial budaya dan geografis. Persamaan yang digunakan dalam menghitungkan risiko bencana yang disajikan sebagai berikut.

$$
\text { Risiko = Bahaya X Kerentanan }
$$

\subsubsection{Kawasan Rawan Bencana Letusan Gunung Kelud}

Kabupaten Blitar menjadi prioritas penataan kawasan rawan bencana dengan jenis bencana letusan Gunung Kelud. Berdasarkan data PVMBG kawasan rawan bencana Gunung Kelud terbagi menjadi tiga kawasan rawan bencana yang diuraikan sebagai berikut.

a. Kawasan Rawan Bencana III (KRB III), yaitu kawasan dengan radius $2 \mathrm{~km}$ dari pusat erupsi, dan memiliki risiko tinggi terdampak awan panas, gas beracun, aliran lava, serta tertimpa lontaran batuan dan hujan abu yang sangat lebat;

b. Kawasan Rawan Bencana II (KRB II), yaitu kawasan dengan radius $5 \mathrm{~km}$ dari pusat erupsi, yang berpotensi terdampak awan panas, aliran lava, serta tertimpa lontaran batuan dan hujan abu yang sangat lebat;

c. Kawasan Rawan Bencana I (KRB I), yaitu kawasan dengan radius $10 \mathrm{~km}$ dari pusat erupsi, yang berpotensi terdampak tertimpa lontaran batuan dan hujan abu.

Selain itu PVMBG juga membagi Gunung Kelud berdasarkan zona lemparan material gunung api sebagai berikut:

a) Zona Lontaran Material I, merupakan kawasan yang memiliki jarak radius 0 $7 \mathrm{~km}$ dari pusat erupsi dan material lontaran berdiameter $64 \mathrm{~mm}$

b) Zona Lontaran Material II, merupakan kawasan yang memiliki jarak radius 7-
$10 \mathrm{~km}$ dari pusat erupsi dan material lontaran berdiameter $20 \mathrm{~mm}$

c) Zona Lontaran Material III, merupakan kawasan yang memiliki jarak radius 10-14 $\mathrm{km}$ dari pusat erupsi dan material lontaran berdiameter $10 \mathrm{~mm}$

Gambar 2 merupakan peta bahaya Gunung Kelud yang disusun berdasarkan uraian di atas. Berdasarkan hasil pemetaan yang disajikan pada gambar 2, luas KRB I adalah $14,78 \%$, KRB II memiliki luasan 7,61 $\%$, KRB III memiliki luasan $77,06 \%$ dari total keseluruhan KRB. Kecamatan gandusari adalah kecamatan dengan tingkat rawan tertinggi karena sebagian wilayahnya berada pada KRB I sebesar 6,09\%, KRB II sebesar 5,13\% dan KRB III sebesar 11,77\%.

\subsubsection{Kerentanan Bencana Gunung Kelud}

Hasil pembobotan masing-masing aspek dari hasil analisis AHP terdiri dari aspek kerentanan lingkung, fisik, sosial dan ekonomi maka selanjutnya dilakukan analisis weighted overlay. Adapun hasil dari overlay setiap aspek tersebut disajikan pada gambar 3 .

Setelah diperoleh skor kerentanan untuk seluruh aspek, penyusunan keseluruhan kerentanan yang didasari oleh Perka BNPB No. 12 tahun 2012. Berikut merupakan formula yang digunakan untuk merumuskan kerentanan bencana gunung api di Kabupaten Blitar.

Kerentanan $=(0.4 *$ skor kerentanan sosial $)+(0.25 *$ skor kerentanan ekonomi $)+$ $(0.25 *$ skor kerentanan fisik $)+(0.1 *$ skor kerentanan lingkungan)

Berdasarkan formula tersebut, pemetaan keseluruhan kerentanan letusan Gunung Kelud di Kabupaten Blitar disajikan pada gambar 4. 


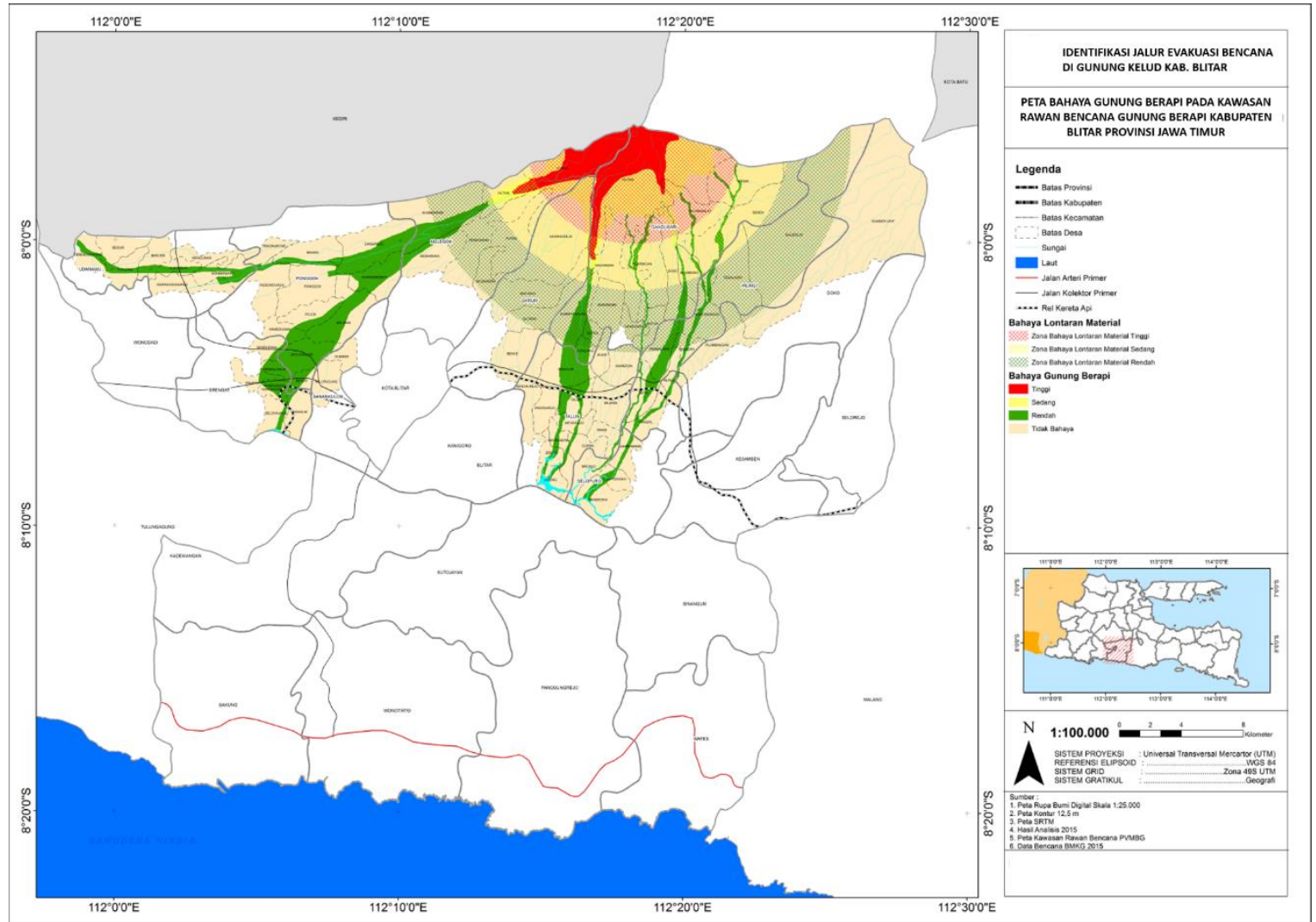

Sumber: Hasil Analisis Tahun 2020

Gambar 2. Peta Bahaya Gunung Api Pada Kawasan Rawan Bencana Gunung Kelud
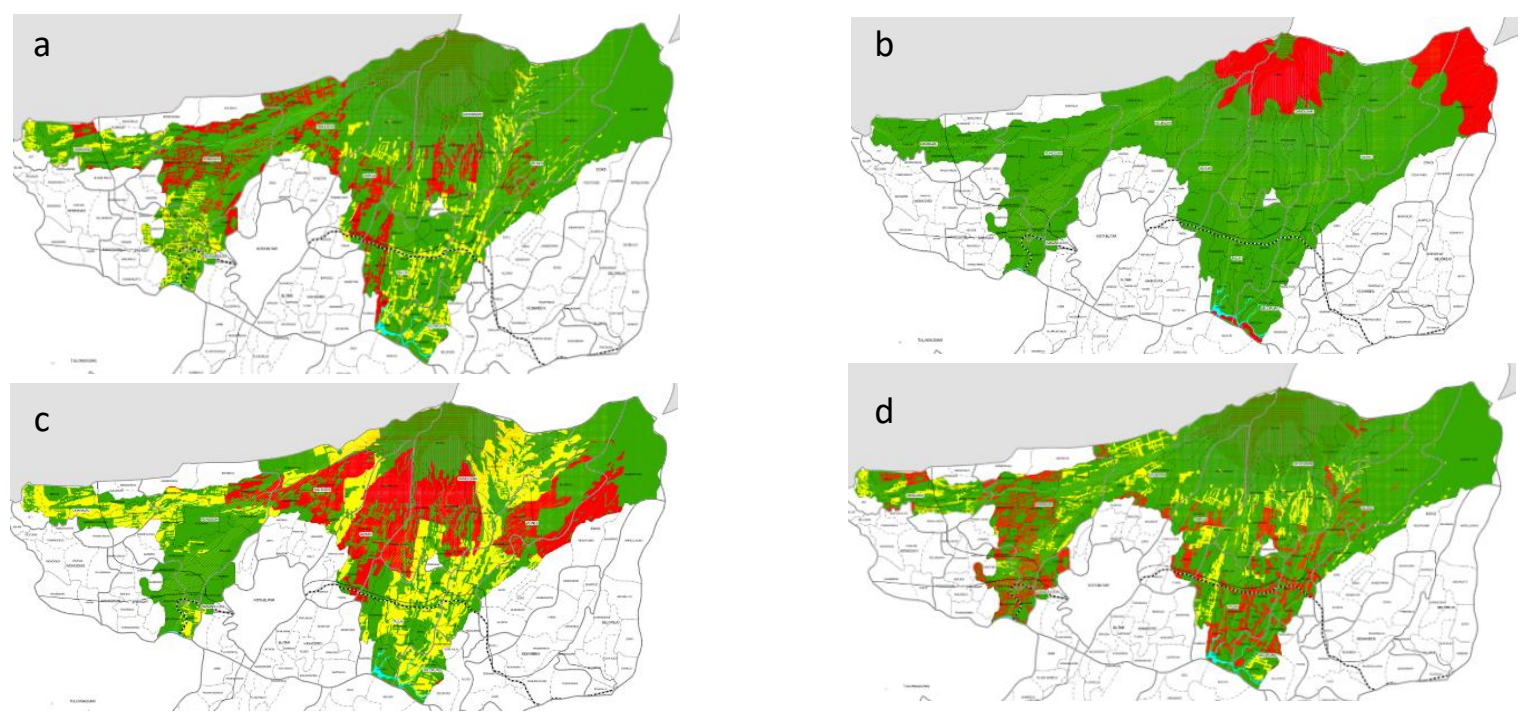

Sumber: Hasil Analisis Tahun 2020

Gambar 3. (a) Peta Kerentanan Lingkungan Pada Kawasan Rawan Bencana Gunung Berapi Kabupaten Blitar, (b) Peta Kerentanan Fisik Pada Kawasan Rawan Bencana Gunung Berapi Kabupaten Blitar, (c) Peta Kerentanan Sosial Pada Kawasan Rawan Bencana Gunung Berapi Kabubaten Blitar 


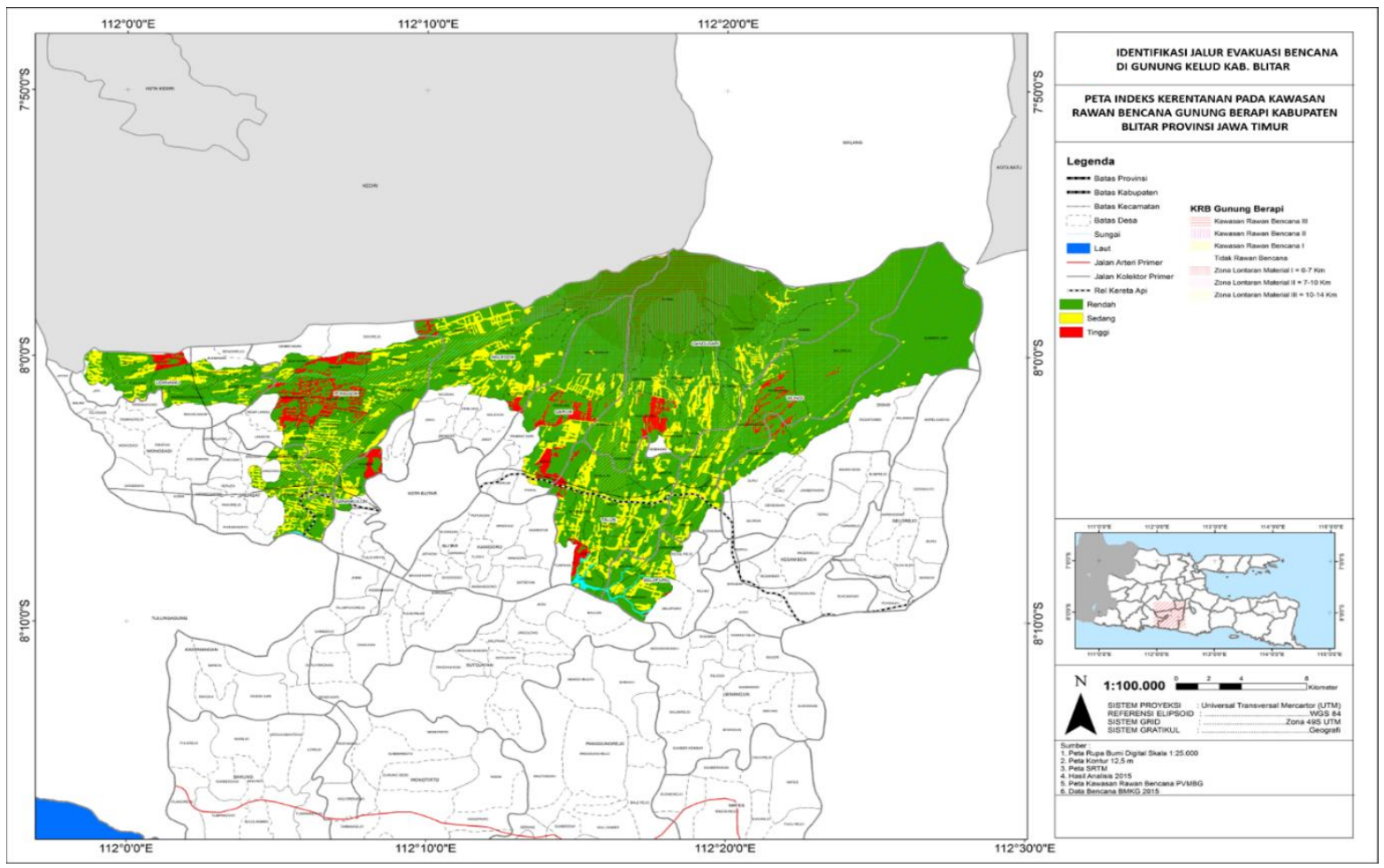

Sumber: Hasil Analisis Tahun 2020

Gambar 4. Peta Indeks Kerentanan Kawasan Rawan Bencana Gunung Api

\subsubsection{Risiko Bencana Letusan Gunung Kelud di Kabupaten Blitar}

Berdasarkan hasil analisis yang telah dilakukan makan hasil dari analisis risiko bahaya letusan Gunung Kelud diketahui bahwa Kecamatan Gandusari merupakan kecamatan dengan prosentase risiko keseluruhan terhadap luas wilayah tertinggi karena sekitar $50,4 \%$ wilayah berada pada kawasan risiko dengan rincian terdapat $39,19 \%$ wilayah dengan risiko tinggi, $19,67 \%$ wilayah dengan risiko sedang dan 16,25\% wilayah pada tingkat risiko rendah. Kecamatan dengan tingkat risiko tertinggi kedua yaitu Kecamatan Ngelgok karena 43,61\% wilayahnya berada pada kawasan rawan bencana dengan tingkat risiko tinggi, sekitar $18,19 \%$ wilayahnya berada pada risiko sedang dan $5,63 \%$ wilayahnya berada pada tingkat risiko rendah. Hasil dari analisis risiko bencana disajikan pada gambar 6 .

\subsection{Risiko Bencana Letusan Gunung Kelud di Kabupaten Blitar}

Perencanaan jalur evakuasi bencana bertujuan untuk mencari jalan tersingkat menuju daerah aman bagi masyarakat yang tinggal di kawasan rawan bencana. Mobilisasi penduduk dari ancaman bahaya bencana gunung berapi melalui jalur evakuasi bencana, terbagi menjadi 2 tahap, yaitu dari permukiman ke tempat evakuasi sementara (TES), dan dari tempat evakuasi sementara menuju tempat evakuasi akhir (TEA). Jalur evakuasi dari permukiman menuju TES dapat ditempuh maksimal 10 menit dari rumah rumah penduduk, berjarak 400 - 600 meter dari pusat permukiman dan dapat ditempuh dengan berjalan kaki maupun dengan moda transportasi. Panjang keseluruhan jalur evakuasi dipengaruhi oleh banyaknya pusat permukiman, jumlah penduduk, jumlah TES serta luas dari desa tersebut. Pada kawasan rawan bencana Gunung Kelud Kabupaten Blitar, terdapat Desa Maliran di Kecamatan Ponggok, Desa Semen dan Desa Soso di Kecamatan Gandungsari yang memiliki keseluruhan jalur evakuasi dari permukiman ke TES terpanjang. Jalur evakuasi Tempat Evakuasi Sementara (TES) ke Tempat Evakuasi Akhir (TEA) ditentukan berada di luar KRB dan memiliki kelengkapan infrastruktur. Untuk itu jalur diarahkan 
agar senantiasa menjauhi sungai yang menjadi aliran lahar dan juga menjauhi zona lontaran material vulkanik. Selain itu, juga dipertimbangkan hierarki jalan yang digunakan sebagai jalur evakuasi, yakni setidaknya memiliki fungsi jalan lokal primer. Hal ini berpengaruh pada waktu tempuh menuju tempat evakuasi akhir terdekat. Pada kawasan rawan bencana Gunung Kelud Kabupaten Blitar, terdapat desa Plumbangan di Kecamatan Doko dan Desa Sumberagung dan Desa Gondang di Kecamatan Gandungsari yang memiliki total jalur evakuasi dari TES ke TEA terpanjang. Adapun jalur evakuasi dari Tempat Evakuasi Sementara ke Tempat Evakuasi Akhir disajikan pada gambar 7.
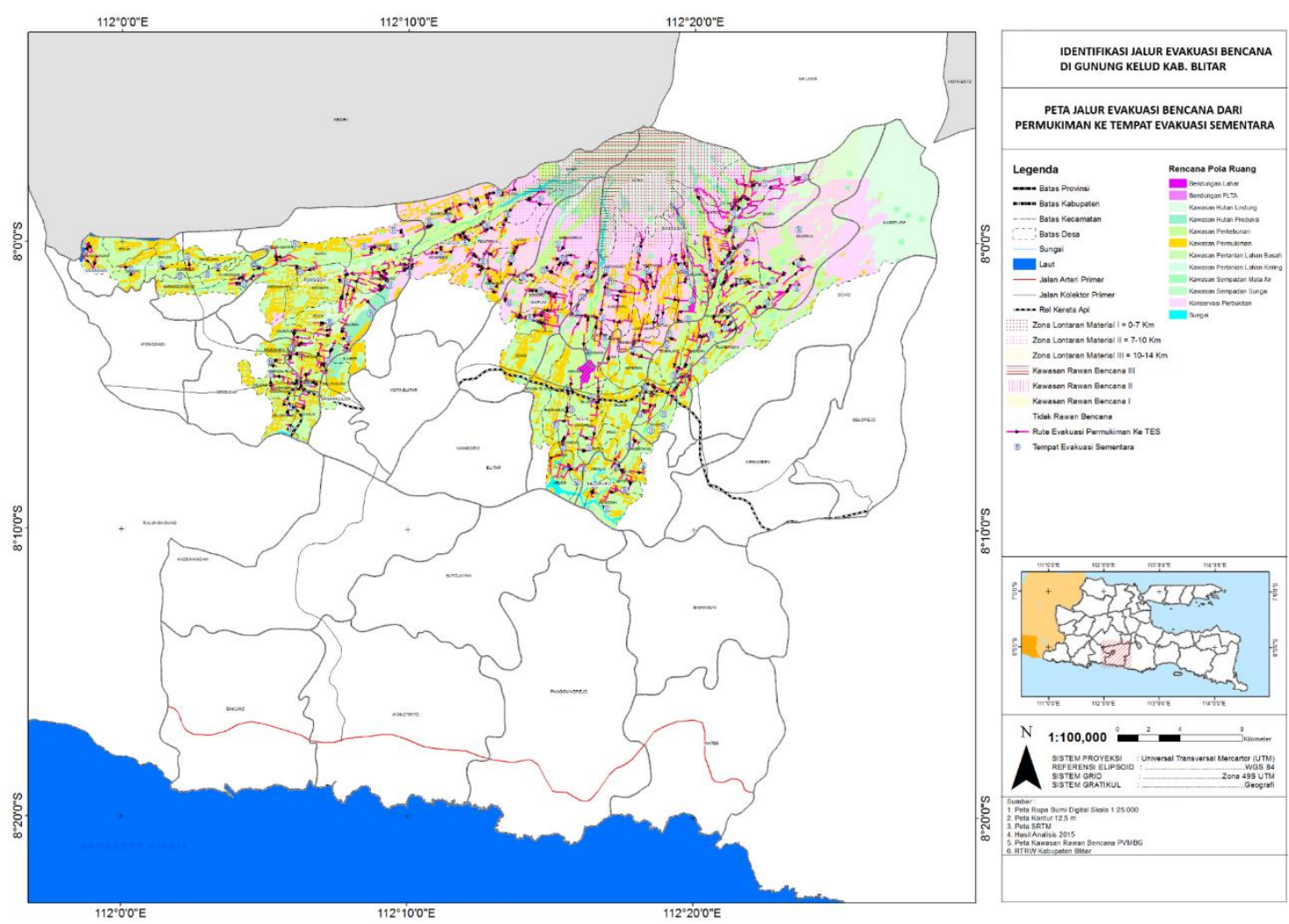

Sumber: Hasil Analisis Tahun 2020

Gambar 5. Peta Indeks Kerentanan Kawasan Rawan Bencana Gunung Api 


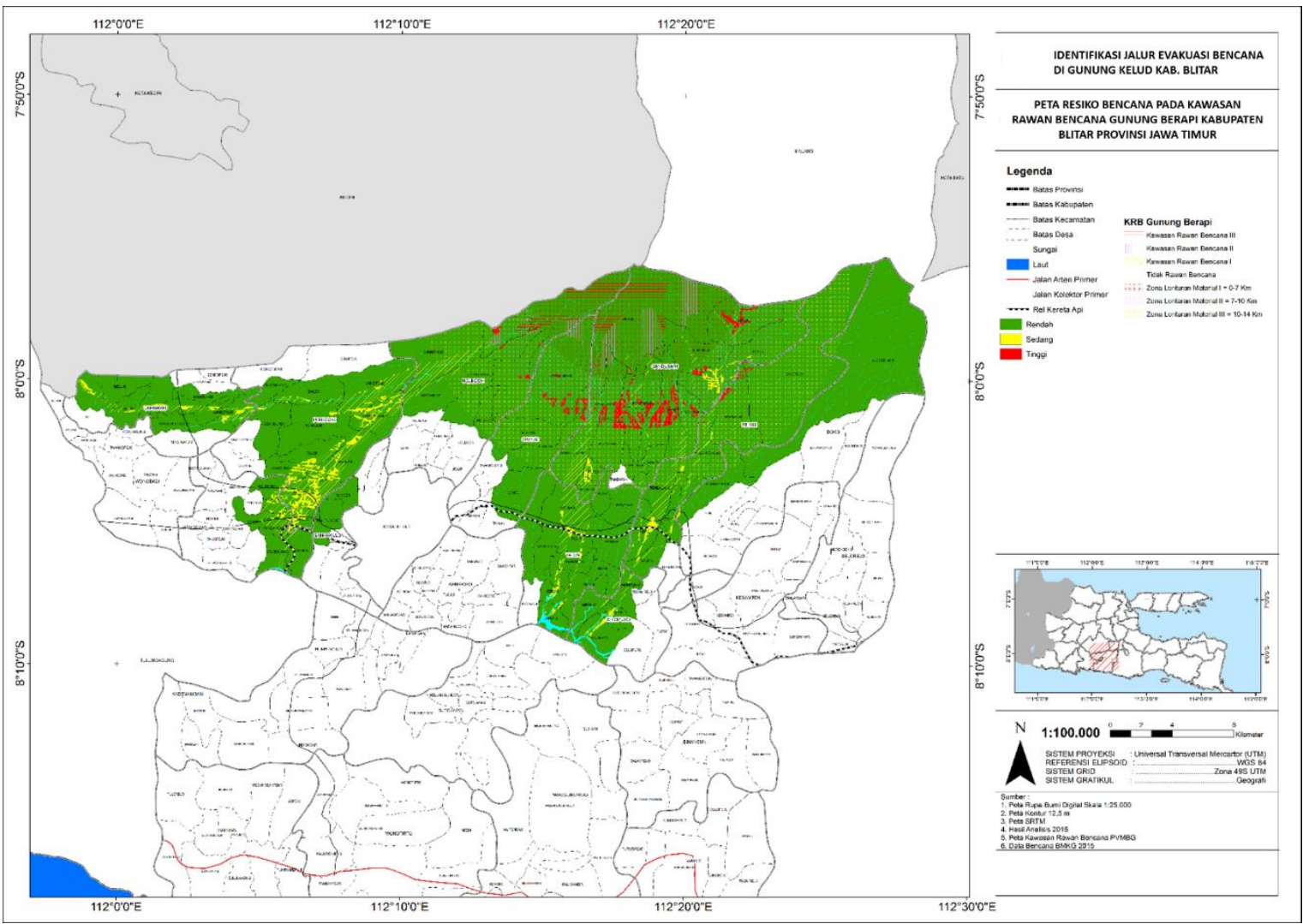

Sumber: Hasil Analisis Tahun 2020

Gambar 6. Peta Risiko Bencana pada Kawasan Rawan Bencana Gunung Kelud
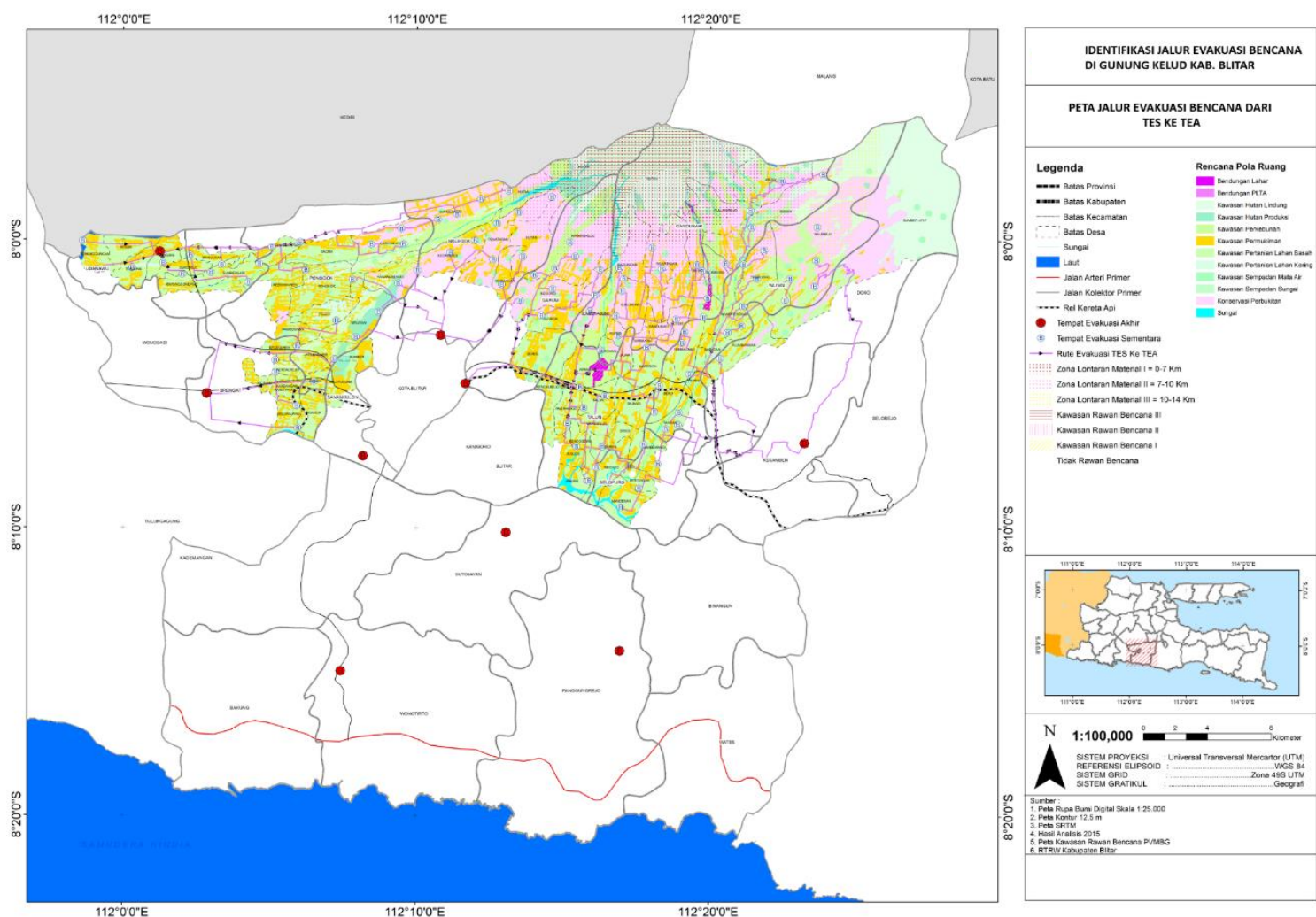

Sumber: Hasil Analisis Tahun 2020

Gambar 7. Peta Jalur Evakuasi Bencana dari TES ke TEA

Jurnal Plano Buana, Vol 1 No 2, April 2021 


\section{KESIMPULAN}

Mobilisasi masyarakat terhadap ancaman bahaya gunung berapi dengan jalur evakuasi memiliki 2 tahapan. Kedua tahapan tersebut terdiri dari evakuasi masyarakat dari permukiman ke tempat evakuasi sementara (TES) dan dari tempat evakuasi sementara menuju tempat evakuasi akhir (TEA). Pada kawasan rawan bencana Gunung Kelud Kabupaten Blitar, terdapat Desa Maliran di Kecamatan Ponggok, Desa Semen dan Desa Soso di Kecamatan Gandungsari yang memiliki keseluruhan jalur evakuasi dari permukiman ke TES terpanjang. Jalur evakuasi dari Tempat Evakuasi Sementara (TES) menuju Tempat Evakuasi Akhir (TEA) ditentukan berada di luar KRB, memiliki kelengkapan infrastruktur, dan menjauhi sungai yang menjadi aliran lahar dan juga menjauhi zona lontaran material vulkanik. Pada kawasan rawan bencana Gunung Kelud Kabupaten Blitar, terdapat desa Plumbangan di Kecamatan Doko dan Desa Sumberagung dan Desa Gondang di Kecamatan Gandungsari yang memiliki total jalur evakuasi dari TES ke TEA terpanjang.

\section{UCAPAN TERIMAKASIH}

Penulis Mengucapkan terimakasih kepada BAPPEDA kab Blitar, Dinas Pekerjaan Umum dan Penataan Ruang Kabupaten Blitar, BPBD Kabupaten Blitar, praktisi dan akademisi yang telah membantu memberikan data penunjang penelitian dan bersedia menjadi narasumber, serta LPPM Institut Teknologi Nasional Malang yang telah memberikan izin untuk melakukan penelitian ini.

\section{REFERENSI}

Awotona, A. (1997). Reconstruction After Disaster: Issues and Practices. Aldershot: Ashgate.
B. Wignyosukarto. (2007). Pengelolaan Sumberdaya Air Terpadu dalam Upaya Pencapaian Tujuan Pembangunan Millenium 2015, Pidato Pengukuhan Guru Besar FT UGM.

Basyid, M. Abdul. (2010). Pengembangan Peta Rencana Kontijensi Bencana Gunung Api, Studi Kasus: Gunung Api Lokon. Jurusan Teknik Geodesi - FTSP Institut Teknologi Nasional, Bandung. LPPM Itenas No.4 Vol. XIV, Oktober Desember.

Bachri, S., Utaya, S., Nurdiansyah, F. D., Nurjanah, A. E., Tyas, L. W., Purnama, D. S., \& Adillah, A. A. (2017). Analisis dan Optimalisasi Potensi Lahan Pertanian sebagai Kajian Dampak Positif Erupsi Gunungapi Kelud 2014. Majalah Geografi Indonesia Vol. 31 No. 2, 33 - 43.

Cross, Jean. (1998). Study Notes SESC9211 Risk Management. University of New South Wales, Department of Safety Science. Sidney, Australia.

Firmansyah. (2011). Identifikasi tingkat risiko bencana letusan Gunung Api Gamalama di Kota Ternate. Jurnal Lingkungan dan Bencana Geologi, Universitas Pasundan. Vol. 2 No. 3 Desember : 203 - 219

Nazir, Mohhamad (1988). Metode Penelitian. Ghalia. Jakarta.

Noor,Djauhari. (2011). Pengantar mitigasi Bencana Geologi

Supriyono.P, Amanda. (2014). Seri Pendidikan Pengurangan Risiko Bencana Gunung Meletus. Jogjakarta. ISBN 978979-29-2325-4. Hal 173-174

Saaty. T. (1993). Pengambilan Keputusan Bagi Para Pemimpin, Proses Hirarki Analitik untuk Pengambilan Keputusan dalam Situasi yang Kompleks, Pustaka Binama Pressindo.

UNISDR. (2009). Terminologi pengurangan Risiko Bencana. 